\title{
Effect of compatibilization in situ on PA/SEBS blends
}

\author{
Anna Paula Azevedo de Carvalho ${ }^{1}$ and Alex da Silva Sirqueira ${ }^{1 *}$ \\ ${ }^{1}$ Laboratório de Tecnologia de Materiais, Universidade Estadual da Zona Oeste - UEZO, \\ Rio de Janeiro, RJ, Brasil \\ *alexsirqueira@uezo.rj.gov.br
}

\begin{abstract}
This paper presents the mechanical, thermal and rheological properties of polymer blends of polyamide 6 (PA) and styrene-butylene-styrene (SEBS) using SEBS-g-MA as a coupling agent. The increase in the interfacial interaction of $\mathrm{PA} / \mathrm{SEBS}$ blends with the addition of SEBS-g-MA was observed to enhance the mechanical properties studied (excellent elongation at break revealed by a 500\% increase). Higher hardness values and a higher degree of crystallinity were obtained for compatibilized blends. In the presence of the SEBS-MA compatibilizer, the heat sweep thermograms obtained by DSC showed only one melting peak, which confirms the effect of the compatibilizer. The best rheological properties were observed for the ternary blends. The lowest concentration of SEBS-g-MA promoted the toughening of PA, and 7.5 phr of compatibilizer increased the modulus E' of the ternary blends compared to that of the binary blends. DMTA analysis allowed for the system to be characterized as partially miscible.
\end{abstract}

Keywords: polyamide, SEBS, compatibilization, rheology, DMTA.

\section{Introduction}

Polymer blends enjoy widespread application in various industries for the development of new materials capable of combining the intrinsic properties of each component and can be obtained by the simple method of physical blending. This class of materials represents an economically viable alternative for various applications because of its low production $\cos ^{[1]}$. Examples of materials in this class are those with a high impact strength consisting of heterophasic systems such as high-impact polystyrene and mixtures of polypropylene and elastomers ${ }^{[2]}$.

Although the materials obtained from polymer blends afford economic advantages, the resulting mixtures of these systems exhibit weaker properties. The synergism of properties is rarely achieved due to various factors such as structural differences, differences in polarity, and the rate of crosslinking among different materials. These effects produce an immiscible blend without the final properties desired. The properties of an immiscible polymer blend are dependent on factors such as the morphology of the system, composition, the rheological and thermal properties of the components, and processing conditions. To improve the performance of heterophasic systems, it is common to use fillers, reinforcing agents and compatibilizers. The addition of small amounts of a third component in the immiscible blend can change the interfacial energy and the dispersion between phases, acting as a compatibilizer ${ }^{[3-4]}$.

Coupling agents are the most widely used non-reactive agents, as they allow for the reaction control required for reactive compatibilizers. Non-reactive agents are usually block or graft and can lead to a reduction in size of the dispersed phase and modifying the mechanical properties of the material. These agents must be compatible with each polymer in a mixture. Selecting the appropriate coupling agent is a great challenge because the choice depends on factors such as molecular weight, chemical structure and interaction between each component in a homopolymer/copolymer mixture ${ }^{[5]}$.

One of the methods used to obtain compatible polymer blends involves the modification of polymers with maleic groups that can be used as coupling agents. The thermoplastic elastomer composed of styrene and butadiene functionalized with maleic anhydride (SEBS-g-MA) has been widely used for compatibilizing polyamides with polypropylene $\mathrm{e}^{[6]}$.

The objective of the present study was to develop a thermoplastic elastomer based on polyamide 6 (PA) and styrene-butylene-styrene (SEBS) to meet the performance requirements of the automotive industry. However, due to the immiscibility between the pair of materials, SEBS-g-MA was used as the coupling agent in the system. It is known that different types of polyamides are amino terminal groups capable of reacting easily with terminal anhydride groups. Figure 1 shows a hypothetical model proposed for the reaction between the amino end groups of PA and the anhydride functional group of SEBS that occurs in the in situ compatibilization mechanism to combine the pair.

\section{Materials and Methods}

\subsection{Materials}

The polyamide- 6 (PA) used in this work was a commercial product from Radici, Italy. The melt flow index, or MFI, (at $230^{\circ} \mathrm{C}$ and $2.16 \mathrm{~kg}$ load) and density were $35 \mathrm{~g} / 10 \mathrm{~min}$ and $1.13 \mathrm{gr} / \mathrm{cm}^{3}$, respectively. Styrene-ethylene/butylene-styrene (SEBS) triblock copolymer containing $30 \mathrm{wt} \%$ styrene and styrene-ethylene/butylene-styrene triblock copolymer grafted with $1.84 \mathrm{wt} \%$ of maleic anhydride (SEBS-g-MA) were supplied by Kraton Polymers as commercial-grade Kraton ${ }^{\circledR}$ G 1650 and Kraton ${ }^{\circledR}$ FG1901, respectively. SEBS-g-MA has been reported to contain a styrene to ethylene/butylene ratio 


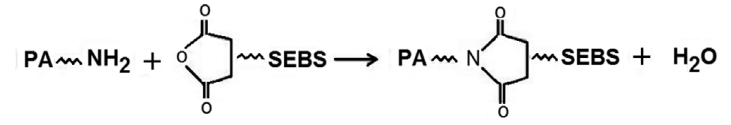

Figure 1. Hypothetical reaction for the formation of PA-SEBS pair.

in the triblock copolymer of 30/70 by weight and an MFI value of $22 \mathrm{~g} / 10 \mathrm{~min}$ (at $230^{\circ} \mathrm{C}$ and $5 \mathrm{~kg}$ load).

\subsection{Preparation of PA/SEBS blends}

Prior to the mixing process, PA, SEBS and SEBS-g-MA were dried at $80^{\circ} \mathrm{C}$ for 24 hours in a vacuum oven. PA/SEBS blends were prepared by a mechanical mixer in a Haake Rheomix OS internal mixer. Polyamide was introduced into the mixer at a set temperature of $260{ }^{\circ} \mathrm{C}$, in a CAM rotor geometry, a rotor speed of 60 RPM, and a fill factor of 0.7 ; after 3 minutes, the SEBS and SEBS-g-MA were mixed for more 5 minutes under the same test conditions. Thus, a total of 8 minutes was required to obtain PA/SEBS blends in a melt state. The sample compositions are reported in Table 1.

\subsection{Characterizations}

\subsubsection{Mechanical properties}

Prior to testing, all specimens were dried in an oven at $80{ }^{\circ} \mathrm{C}$ for 10 hours. Tensile tests were performed using a Universal Machine Test (EMIC model 422- Brazil) at room temperature according to ASTM D638; sample type IV was used at a cross-head speed of $100 \mathrm{~mm} / \mathrm{min}$. The Shore D hardness was recorded over $1 \mathrm{~s}$ after a presser foot contacted each sample, according to ASTM D2240 (Bareiss Hardness - Germany).

\subsubsection{Swelling}

The specimens to be tested in swelling were immersed in a bottle containing engine oil (Petrobras $15 / 50 \mathrm{~W}$, Brasil) at $80^{\circ} \mathrm{C}$ for 70 hours, according to ASTM D316-95. Thereafter, the specimens were removed from the oil, quickly dipped in toluene, and blotted lightly with filter paper to eliminate excess oil on the specimen surfaces. The degree of swelling was calculated by Equation 1:

$$
\text { Swelling }(\%)=\frac{\mathrm{W}_{\mathrm{b}}-\mathrm{W}_{\mathrm{a}}}{\mathrm{W}_{\mathrm{b}}} \times 100
$$

where $\mathrm{W}_{\mathrm{b}}$ is the weight before swelling and $\mathrm{W}_{\mathrm{a}}$ is the weight after swelling.

\subsubsection{Thermal analysis}

The thermal behaviours of the melting temperature $\left(\mathrm{T}_{\mathrm{M}}\right)$ and enthalpy of fusion $\left(\Delta \mathrm{H}_{\mathrm{f}}\right)$ were obtained by differential scanning calorimetry (DSC) using a Maia F3 instrument. The analyses were performed under inert conditions with a $\mathrm{N}_{2}$ flow rate of $50 \mathrm{ml} / \mathrm{min}$ and a heating rate of $20^{\circ} \mathrm{C} / \mathrm{min}$. All sample masses were approximately $5 \mathrm{mg}$. Melting thermograms were obtained after the second heating run. The degree of crystallinity $\left(\mathrm{X}_{\mathrm{C}}\right)$ of the blends was calculated from the ratio of the enthalpy of fusion of the PA/SEBS mixture and the enthalpy of fusion of $100 \%$ crystalline polyamide $6\left(\Delta \mathrm{H}_{\mathrm{PA} / \mathrm{SEBS}} / \Delta \mathrm{H}_{\mathrm{PA}}\right)$, where $\Delta \mathrm{H}_{\mathrm{PA}}=190,8 \mathrm{~J} . \mathrm{g}^{-1[7]}$.
Table 1. Formulation of mixtures PA/SEBS.

\begin{tabular}{ccc}
\hline $\begin{array}{c}\text { PA } \\
(\text { Phr })\end{array}$ & $\begin{array}{c}\text { SEBS } \\
\text { (Phr) }\end{array}$ & $\begin{array}{c}\text { SEBS-g-MA } \\
\text { (Phr) }\end{array}$ \\
\hline 50 & 50 & - \\
50 & 45 & 5.0 \\
50 & 42.5 & 7.5 \\
50 & 35 & 15 \\
\hline
\end{tabular}

\subsubsection{Dynamic mechanical analysis (DMA)}

The dynamic mechanical properties of the PA/SEBS blends were measured using a dynamic mechanical analyser from TA Instruments. Properties including tan delta and the storage modulus ( $E^{\prime}$ ) of the PA/SEBS blends were examined in the bending mode of deformation at a heating rate of $10{ }^{\circ} \mathrm{C} / \mathrm{min}$ and a frequency of $1 \mathrm{~Hz}$ from -130 to $130^{\circ} \mathrm{C}$.

\subsubsection{Thermogravimetric analysis (TGA)}

Thermogravimetric analysis was performed on a TGA instrument from TA Instruments under a nitrogen atmosphere and at a heating rate of $10{ }^{\circ} \mathrm{C} / \mathrm{min}$. A small amount (approximately $9 \mathrm{mg}$ ) of specimen was used for analysis. The weight loss of the specimen was measured as a function of temperature.

\subsubsection{Rheological properties}

Rheological analyses were performed on a Haake rheometer - MARS model, from Thermo Scientific Instruments using a parallel plate geometry with a plate diameter of $25 \mathrm{~mm}$ and a gap of $1 \mathrm{~mm}$. The complex viscosity $(\eta *)$, the shear storage modulus ( $\left.\mathrm{G}^{\prime}\right)$ and the shear loss modulus (G') of the binary and ternary blends were measured at $260^{\circ} \mathrm{C}$ over the frequency range of 0.01 to $15 \mathrm{~Hz}$ with a strain of $1 \%$. It was ensured that all experiments were performed in the linear viscoelastic regime. The complex strain sweeps were performed at a frequency of $1 \mathrm{~Hz}$ to determine the region of linear behaviour of the viscoelastic material. The strain rate used ranged from 0.1 to $600 \%$.

\section{Results and Discussions}

\subsection{Torque rheometry}

Torque rheometry has frequently been used to monitor chemical reactions during reactive melt mixing. The torque-time behaviour of the PA/SEBS/SEBS-g-MA blend is shown in Figure 2. The compatibilizer (SEBS-g-MA) was added to PA/SEBS after 4 minutes of processing in an internal mixer, when the PA was duly melted and SEBS plasticized. When 5 phr of SEBS-g-MA was added to the PA/SEBS mixture, an increase in torque was observed. This effect can be attributed to the reaction between MA and the amine group in PA. According to Roeder et al. ${ }^{[8]}$, Jiang et al. ${ }^{[9]}$ and Bassani et al. ${ }^{[10]}$, the anhydride groups of SEBS-g-MA react with the terminal amine groups of PA 6 , forming an imide group and resulting in a copolymer in situ at the interface. Figure 1 illustrates a hypothetical reaction for the formation of the PA-SEBS pair. The reaction between the anhydride groups of SEBS-g-MA and terminal amine groups of PA involves the formation of water as a 
byproduct, which can lead to the degradation of the PA chains by hydrolysis. However, Figure 2 shows that the end torque of the PA/SEBS/SEBS-g-MA blend remained constant, which indicates that no degradation occurred. Regarding the other torque curves of PA/SEBS, it should be noted that the blend containing $7.5 \mathrm{phr}$ of compatibilizer showed the highest torque, indicating that a high content of SEBS-g-MA promotes a highly effective reaction with PA. The sample containing $15 \%$ SEBS-MA showed the same behaviour as that observed for the sample containing $7.5 \mathrm{phr}$ of compatibilizer.

\subsection{Mechanical properties}

The effect of compatibilization on the mechanical properties of tensile strength was evaluated. Table 2 presents the tensile strength at break, elongation at break, MFI and hardness for the blends studied. The addition of SEBS-g-MA to the PA/SEBS blends yielded higher tensile strength and elongation at break. The tensile strength for the samples containing 5 and $7.5 \mathrm{phr}$ of compatibilizer increased by approximately $100 \%$. The melt index flow showed the highest values for the compatibilized blend, likely due to the compatibilizer's effect in anchoring the phases, which reduced the distance between PA and SEBS. The increase in the mechanical properties studied (tensile, elongation, feasibility to flow and hardness) can be explained by an increase in molecular weight due to the compatibilization reaction, leading to a reduction in the interfacial tension between different phases and consequently the average particle size of the dispersed phase. Compared with that measured for the binary blend, a significant increase in the elongation at break for the compatibilized blends was observed, reaching a strain of $500 \%$. This behaviour can be attributed to the improvement of the interaction between dispersed phase and matrix with the incorporation of SEBS-g-MA. In some cases, the hardness of a material defines its applicability. Table 2 presents the hardness values for the PA/SEBS blends. The compatibilized blends showed higher hardness values compared to those of the PA/SEBS blends. This behaviour was due to the incorporation of SEBS into the polyamide matrix, which was favoured by the effects of the compatibilizer. It was observed that the addition of $5 \mathrm{phr}$ of SEBS-g-MA improved all mechanical properties.

The effect of the compatibilizer on the physical properties of swelling in oil is illustrated in Figure 3. The degree of swelling decreased by approximately $70 \%$ for the mixtures containing SEBS-g-MA. The addition of a compatibilizing agent to the system reduced the interfacial tension, causing an increase in the interaction between the phases. It is

Table 2. Mechanical properties of elongation at break, tensile strength, melt index flow and hardness for the PA/SEBS and PA/SEBS/SEBS-g-MA mixtures.

\begin{tabular}{ccccc}
\hline $\begin{array}{c}\text { PA/SEBS/ } \\
\text { SEBS-g- } \\
\text { MA (Phr) }\end{array}$ & $\begin{array}{c}\text { Elongation } \\
\text { at break } \\
(\%)\end{array}$ & $\begin{array}{c}\text { Tensile } \\
\text { strength } \\
\mathbf{( M P a )}\end{array}$ & $\begin{array}{c}\text { MFI } \\
(\mathbf{g} / \mathbf{1 0} \text { min) }\end{array}$ & $\begin{array}{c}\text { Hardness } \\
\text { (Shore D) }\end{array}$ \\
\hline $50 / 50 / 00$ & $159 \pm 49$ & $17.9 \pm 0.7$ & $7.2 \pm 5.0$ & $52 \pm 7$ \\
$50 / 45 / 5.0$ & $798 \pm 55$ & $32.9 \pm 2.5$ & $12.7 \pm 0.9$ & $60 \pm 1$ \\
$50 / 42.5 / 7.5$ & $730 \pm 40$ & $30.5 \pm 0.9$ & $13.1 \pm 0.5$ & $57 \pm 1$ \\
$50 / 35 / 15$ & $486 \pm 62$ & $20.4 \pm 1.3$ & $12.4 \pm 0.3$ & $60 \pm 2$ \\
\hline
\end{tabular}

possible that the compatibilizing agent has promoted the presence of a third phase or an interface that has low affinity for the oil, preventing the penetration of small molecules, which explains the decrease in the degree of swelling of the PA/SEBS/compatibilizer mixtures ${ }^{[1]}$.

\subsection{Thermal analysis}

Figure 4 shows the thermogram obtained for the fusion of PA and the PA/SEBS PA/SEBS/SEBS-g-MA blends. The figure shows that PA has two fusion peaks. These two peaks are commonly observed in PA and are assigned to different crystalline forms, i.e., $\alpha$ and $\gamma$, as reported in the literature ${ }^{[12]}$. The peak with the highest TM corresponds to the crystalline structure $\alpha$, and the lower peak corresponds to the $\gamma$ crystalline portion. The literature ${ }^{[6]}$ suggests that the calculation of both XC and TM allow for a better understanding of the results. The PA/SEBS thermograms showed two TM peaks, but the compatibilizer blend showed a tendency to form a peak, reflecting the effect of SEBS-MA in reducing the interfacial tension.

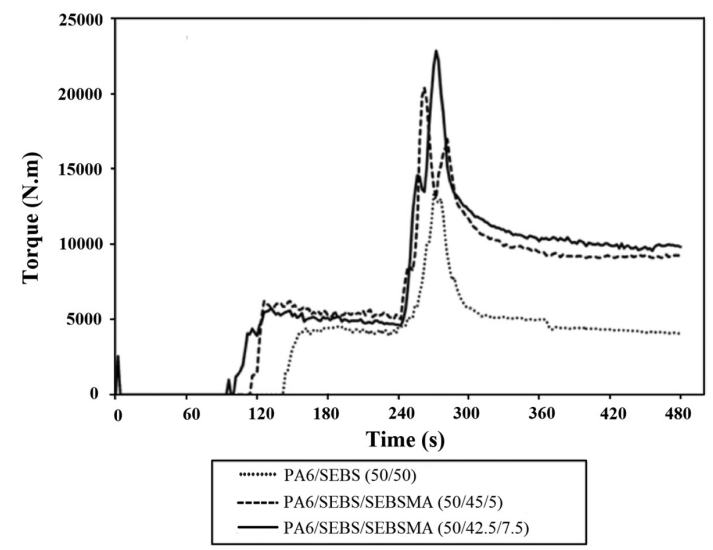

Figure 2. Curves ilustring torque rheometry as a function of time for PA/SEBS and PA/SEBS/SEBS-g-MA mixtures.

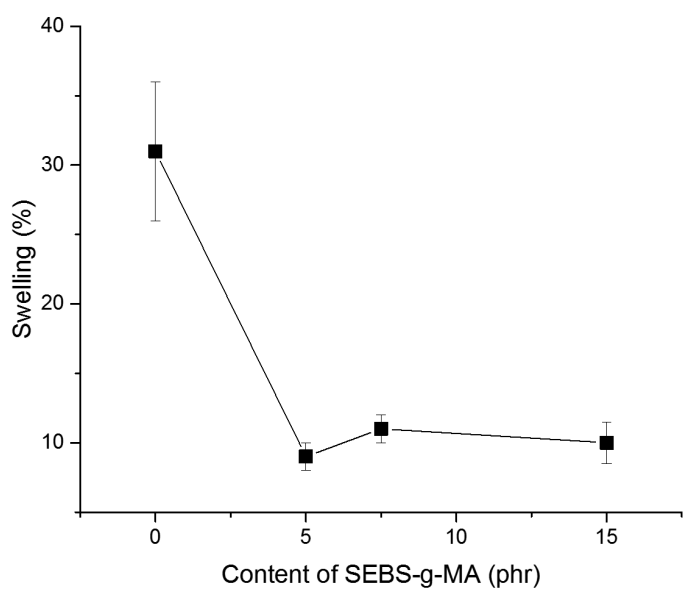

Figure 3. Properties of swelling for PA/SEBS and PA/SEBS/ SEB-g-MA mixtures. 

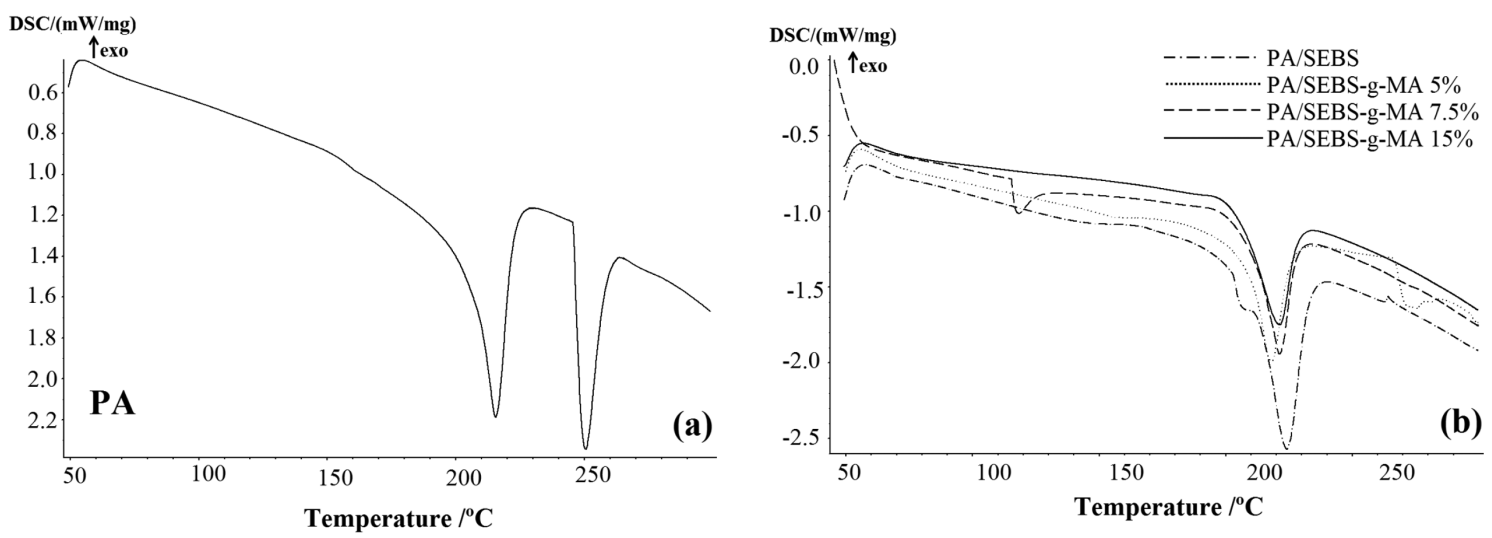

Figure 4. Melting thermograms of PA (a) and the binary and ternary mixtures (b).

Table 3. Thermal properties for binary and PA/SEBS/SEBS-g-MA mixtures.

\begin{tabular}{cccc}
\hline $\begin{array}{c}\text { PA/SEBS/ } \\
\text { SEBS-g-MA } \\
(\mathbf{P h r})\end{array}$ & $\mathbf{T}_{\mathbf{M}}\left({ }^{\circ} \mathbf{C}\right)$ & $\boldsymbol{\Delta H}(\mathbf{J} / \mathbf{g})$ & $\mathbf{X c}_{\mathbf{P A}_{\mathbf{A}}}(\mathbf{\%})$ \\
\hline $100 / 00 / 00$ & $233^{*}$ & $45.36 / 26.11$ & $15^{*}$ \\
$50 / 50 / 00$ & 224 & 57 & 16 \\
$50 / 45 / 5.0$ & 218 & 32 & 17 \\
$50 / 42.5 / 7.5$ & 221 & 29 & 15 \\
$50 / 35 / 15$ & 221 & 30 & 16 \\
\hline
\end{tabular}

*Average between TM and XcPA corresponding to $\alpha$ and $\gamma$ crystalline portions.

Table 3 presents the thermal properties measured for each of the different compositions. The presence of SEBS-g-MA decreased $\mathrm{T}_{\mathrm{M}} \mathrm{PA}$; however, two melting peaks were observed for these blends, demonstrating the immiscibility of the system. For the compatibilized blends, the thermograms of heating showed only one melting peak, which confirmed the effect of the compatibilizer. The reduction in the TM values of the ternary mixtures may reflect changes in the distribution of the crystallites of PA.

The presence of SEBS-g-MA also reduced the XC of the ternary mixtures, which approached the Xc of pure PA. Marco et al. ${ }^{[13]}$ performed experiments using PP/PA6/PP-MA as a compatibilizer and also reported a decrease in the XC of PA6 using a coupling agent. This behaviour can be explained by the decrease in mobility due to the grafting of PA6. This result confirms the hardness results obtained.

\subsection{Dynamic mechanical thermal analysis}

Dynamic mechanical thermal analysis involves applying an oscillating force on a sample and is very efficient characterizing viscoelastic polymeric systems, breaking down the module into an elastic component and a viscous component. Studying the dependence of visco-elastic properties on temperature allows for the determination of the modulus of elasticity and the damping value ${ }^{[14]}$.

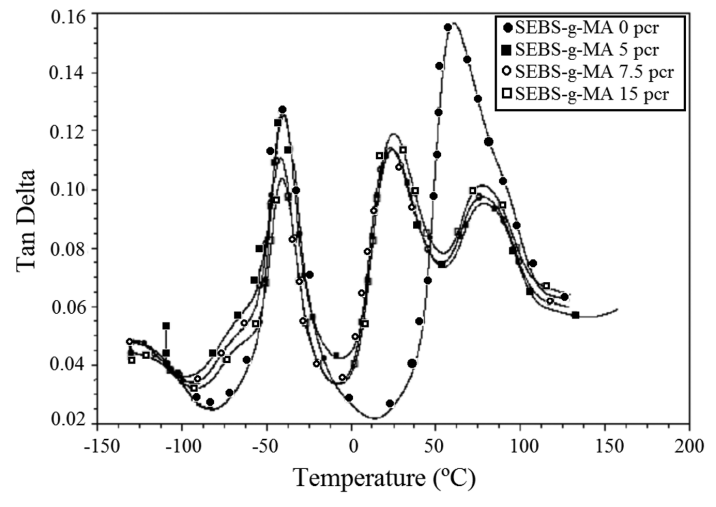

Figure 5. Effect of the presence of a coupling agent on the tan delta values of binary and ternary PA/SEBS mixtures.

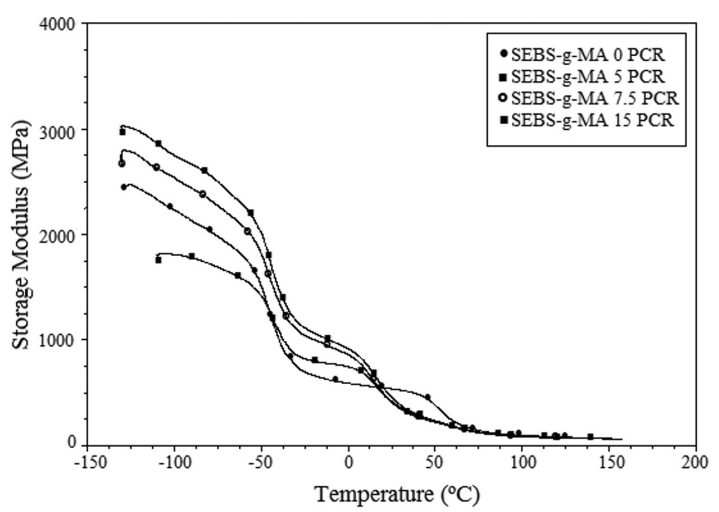

Figure 6. Effect of the presence of a coupling agent on the storage modulus of binary and ternary PA/SEBS mixtures.

Figures 5 and 6 shows the thermodynamic-mechanical properties obtained by DMTA analysis for the binary and compatibilized blends. The damping properties (tan delta) are shown in Figure 5. The PA/SEBS blend (50/50) showed behaviour expected for immiscible systems, 
demonstrating two peaks, one peak corresponding to PA and another corresponding to SEBS. The PA/SEBS blends showed the $\mathrm{T}_{\mathrm{g}}$ of $\mathrm{PA}$, at a temperature close to $60^{\circ} \mathrm{C}$, and the $\mathrm{T}_{\mathrm{g}}$ of the copolymer, close to $-40{ }^{\circ} \mathrm{C}$. The ternary blends (PA/SEBS/SEBS-g-MA) showed a third peak temperature at approximately $23{ }^{\circ} \mathrm{C}$ (located between the $\mathrm{T}_{\mathrm{g}}$ of SEBS and $\mathrm{T}_{\mathrm{g}}$ of PA) and an increase in the $\mathrm{T}_{\mathrm{g}}$ of PA, which rose to $80^{\circ} \mathrm{C}$. The third peak can be explained by the presence of the SEBS-g-MA giving rise to the formation of micro-bridge stages, generating a PA-SEBS pair (see Figure 1). The strong interactions between MA along the SEBS backbone and amine groups gave rise to a decrease in damping. Despite the decrease in damping, the SEBS-MA blends also displayed a slight shift in the glass transition temperature towards lower values. The shift in $\mathrm{T}_{\mathrm{g}}$ can be related to increased interfacial interactions and reduced slip. For the compatibilized blends, it was observed that $15 \mathrm{phr}$ of SEBS-MA reduced the damping in the low-temperature region and $5 \mathrm{phr}$ of SEBS-MA reduced the damping in the PA region.

The storage modulus (E') is a very important property for evaluating the mechanical behaviour of a polymeric composite. Figure 6 shows a vitreous plateau and a reduction in the modulus E' of the ternary mixture with 5 phr of SEBS -g-MA compared with the binary mixture. This result is due to the lower crystallinity of this sample, which favours the toughening of PA. For blends containing a higher content of compatibilizer ( 7.5 and $15 \mathrm{phr}$ ), an increase in the modulus E' was observed. This effect can be explained by the increased interfacial interaction between the phases causing better stress distribution at the interface, which imparted greater rigidity to that sample ${ }^{[15]}$. It is interesting to note that no significant changes occurred in the blends containing a high amount of SEBS-MA (15 phr). It is likely that the system was saturated at $7.5 \mathrm{phr}$.

\subsection{Rheological properties}

The rheological properties of polymers are the most important for processing because they affect all processes involving the flow of material. Viscosity is the property that characterizes the rheological behaviour of polymers. The viscosity value indicates the resistance of a polymer to a given type of flow and shear that may be permanent or oscillatory. The study of the viscosity of polymer blends allows for the evaluation of, among other factors, interactions between the different phases in the blends, such as the interfacial tension ${ }^{[16]}$.

Figure 7 shows the curves of the elastic modulus $\left(G^{\prime}\right)$ and viscous modulus (G") as a function of frequency for the PA/SEBS and PA/SEBS/SEBS-g-MA blends. It should be noted that in the low-frequency region, all samples showed an elastic modulus superior to the viscous modulus. In this study, $G^{\prime}$ increased as the amount of SEBS-MA increased, likely due to the MA and amine reactions. At high frequency, when the material response is similar to that of an elastic solid, all compatibilized blends showed the following relation G'> G'; only non-compatibilized blends showed the inverse behaviour.
This behaviour can be attributed to the increase in the molecular weight by the strong interfacial interaction caused by the compatibilization ${ }^{[17]}$; in others words, SEBS-MA acted as a reactive interfacial agent. Figure 8 shows the relationship between the viscosity and shear rate; it should be noted that all compatibilized blends showed a higher viscosity than the non-compatibilized blends in the linear viscoelastic region (LVR)

\subsection{Thermogravimetry}

To test the thermal stability of the non-compatibilized and compatibilized blends, thermogravimetric analysis (TGA) was performed. Figure 9 compares the thermograms of the PA/SEBS blends. The degradation of the non-compatibilized PA6/SEBS blends occurred at a lower temperature than that the compatibilized blends. The non-compatibilized PA/SEBS blends showed two degradation steps, which can be related to the PA6 and SEBS phases. However, it is interesting to note that the compatibilized blends showed a single degradation step due to the anchoring effect that occurred between the PA6 and SEBS phases, increasing the thermal stability. The high amount of SEBS-MA did not promote the thermal stability of the blends.

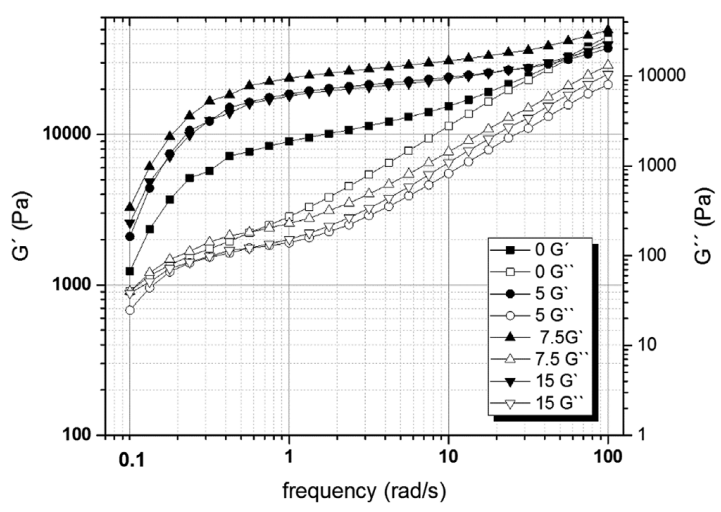

Figure 7. G' and G" as a function of $\omega$ for PA/SEBS non-compatibilized and compatibilized blends.

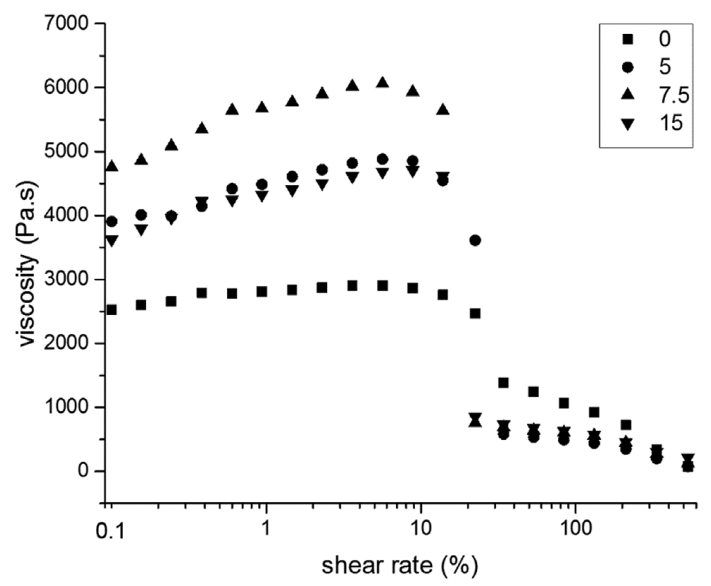

Figure 8. Viscosity as a function of shear rate for PA/SEBS non-compatibilized and compatibilized blends. 


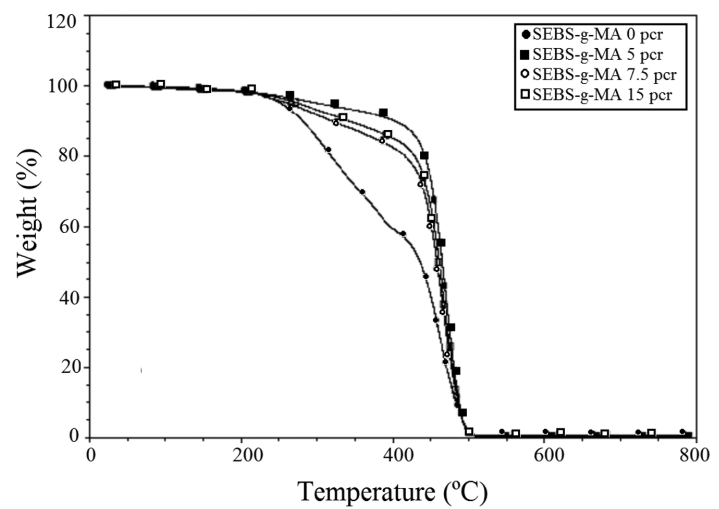

Figure 9. TGA results obtained for PA/SEBS blends.

\section{Conclusions}

The results of this study show that SEBS-g-MA acts as a compatibilizer in mixtures of polyamide and SEBS. The increase in the interfacial interaction of PA/SEBS blends with the addition of SEBS-g-MA proved to increase the mechanical properties studied (excellent elongation at break) and also increased the Tg of PA. Furthermore, higher hardness values and a higher degree of crystallinity were observed for compatibilized blends. The best rheological properties were observed for ternary mixtures. A lower concentration of SEBS-g-MA promoted the toughening of PA and 7.5 phr of compatibilizer increased the modulus E' of the ternary blends compared to that of the binary blends. DMTA analysis allowed for the blend system to be characterized as partially miscible. Based on the results obtained for all of the properties, the best SEBS-MA concentration was $5 \mathrm{phr}$. Furthermore, this concentration improved the thermal stability of the blends in particular.

\section{Acknowledgements}

The authors acknowledge the support of the Laboratory of Polymer Blends and Composite Conductors (LMPCC/IMA-UFRJ) and the Laboratory of Processing and Characterization of Materials (LPCM - INT) in testing the rheological behaviour of the materials formed in this study, the CNPq, FAPERJ and Centro Universitário da Zona Oeste (UEZO) for financial support.

\section{References}

1. Utracki, L.A. (1989). Polymer alloys and blends: thermodynamics and rheology. New York: Hanser Publisher.

2. Pavlidou, S., \& Papaspyrides, D. (2008). A review on polymer-layered silicate nanocomposites. Progress in Polymer Science, 33(12), 1119-1139. http://dx.doi.org/10.1016/j. progpolymsci.2008.07.008.

3. Paul, D. R., \& Robeson, L. M. (2008). Polymer technology: nanocomposites. Polymer, 49(15), 3187-3204. http://dx.doi. org/10.1016/j.polymer.2008.04.017.
4. Maglio, G., \& Palumbo, R. (1994). The role of interfacial agents in polymer Blends, Processing, Morphology and Properties. New York: Plenum Press.

5. Gomes, S. A., Barbosa, R. V., \& Soares, B. G. (1992). Agentes compatibilizantes não reativos para blendas polimericas. I. síntese de poli(etileno-co-acetato de vinila-G-estireno). Polimeros: Ciência e Tecnologia, 2, 19-24. Retrieved in 21 June 2015, from http://revistapolimeros.org.br/articles/view/ $\mathrm{id} / 515 \mathrm{c} 6 \mathrm{c} 9 \mathrm{e} 1 \mathrm{ef} 1 \mathrm{fae} 740000540$

6. Fiegenbaum, F. (2007). Estudo da compatibilização das blendas PP/PA e PP/EPR (Master's dissertation). Universidade Federal do Rio Grande do Sul, Porto Alegre.

7. Kusomoto, Ishak, M. Z. A., Chow, W. S., Takeichi, T., \& Rochmadi. (2008). Influence of SEBS-g-MA on morphology, mechanical and thermal properties of PA/PP/organoclay nanocomposites. European Polymer Journal, 44, 1023-1029. http://dx.doi.org/10.1016/j.eurpolymj.2008.01.019

8. Roeder, J., Oliveira, R. V. B., Gonçalves, M. C., Soldi, V., \& Pires, A. T. N. (2002). Polypropylene/polyamide-6 blends: influence of compatibilization agent on interface domains. Polymer Testing, 21(7), 815-821. http://dx.doi.org/10.1016/ S0142-9418(02)00016-8.

9. Jiang, C., Filippi, S., \& Magagnini, P. (2003). Reactive compatibilizer precursors for LDPE/PA6 blends. I: maleic anhydride grafted polyethylenes. Polymer, 44(8), 2144-2149. http://dx.doi.org/10.1016/S0032-3861(03)00133-2.

10. Bassani, A.; Hage, E., Jr.; Persan, L. A.; Machado, A. V., \& Covas, J. A. (2005). Evolução da morfologia de fases de blendas PA6/AES em extrusora de dupla rosca e moldagem por injeção. Revista Polímeros: Ciência e Tecnologia, 15, 176185. http://dx.doi.org/10.1590/S0104-14282005000300007

11. Almeida, M. S. M. (2006). Compatibilização reativa e vulcanização dinâmica em misturas de polipropileno e borracha nitrílica (Doctoral thesis). Universidade Federal do Rio de Janeiro, Rio de Janeiro.

12. Shi, D., Ke, Z., Yang, J., Gao, Y., Wu, J., \& Yin, J. (2002). Rheology and morphology of reactively compatibilized/PA6 blends. Macromolecules, 35(21), 8005-8012. http://dx.doi. org/10.1021/ma020595d.

13. Marco, C., Ellis, G., Gómez, M. A., Fatou, J. G., Arribas, J. M., Campoy, I., \& Fontecha, A. (1997). Rheological properties, crystallization, and morphology of compatibilized blends of isotactic polypropylene and polyamide. Journal of Applied Polymer Science, 65, 13-20. http://dx.doi.org/10.1002/(SICI)10974628(19970926)65:13<2665::AID-APP8>3.0.CO;2-9.

14. Campbell, D., Pethrick, R. A., \& White, J. R. (2000). Polymer characterization: physical techniques. New York: Hanser Publisher.

15. Sanchez, A., Rosales, C., Laredo, E., Muller, A. J., \& Pracella, M. (2001). In situ fibrillar reinforced PET/PA6/PA66. Polymer Science Engineer, 41, 205-208. http://dx.doi.org/10.1002/ pen.10721.

16. Walters, K. (1989). An introductiuon to rheology. Amsterdam: Elsevier Press.

17. Ollshom, B., Hassander, H., \& Tornell, B. (1998). Improved compatibility between polyamide and polypropylene by the use of maleic anhydride grafted SEBS. Polymer, 39, 26-33. http://dx.doi.org/10.1016/S0032-3861(97)10290-7.

Received: June 21, 2015 Revised: Sept. 07, 2015 Accepted: Oct. 08, 2015 